\title{
Insulin Delivery: An Ever Changing Frontier
}

\author{
Muhammad Salman Tahir Janjua ${ }^{1 *}$ and Jeffrey Joseph \\ ${ }^{1}$ Resident, Department of Anesthesiology and Preoperative Medicine, Augusta University Hospital, Augusta, GA. \\ ${ }^{2}$ Professor and Vice Chair Artificial Pancreas Center, Department of Anesthesiology, Thomas Jefferson University, Philadelphia, PA.
}

Received: April 4, 2016; Accepted: November 10, 2016; Published: November 22, 2016

*Corresponding author: Muhammad Salman Tahir Janjua, M.B.B.S., Resident, Department of Anesthesiology \& Preoperative Medicine, Augusta University, Augusta, Georgia, Tel:878-777-3029;E-mail: mjanjua@augusta.edu

\begin{abstract}
Insulin transport across vascular endothelial cells is the rate limiting step in its time action profile. Glucose uptake in response to insulin is estimated through different techniques and is influenced by insulin sensitivity of the tissue. Glucose clamp technique and minimal model imply an incremental increase in the levels of insulin in the ISF compartment evidenced by increase in glucose uptake. This can not merely be explanied by tissue capillary recruitment or increase in blood flow of already perfused areas. Although insulin is proven to affect the blood flow and capillary recruitment of already perfused areas, restoration of muscle blood flow in insulin resistant patients does not revert the insulin activity profile. By review of frequently cited articles, it can be interpreted that insulin causes a much greater increase in tissue recruitment by increasing the perfused capillary volume of previously unperfused areas, an increase in the permeability of the capillaries and recruitment of insulin transport receptors. This also results in an Increase in volume of distribution of glucose. Insulin, like other proteins, may be transported across by simple diffusion, paracellular pathway and transcellular pathway with the help of transport receptors. In conclusion, insulin is most likely transported across capillary endothelial cells by more than one mechanism and there may be recruitment of these pathways according to insulin levels. Thus further investigations of these possible pathways may help pave the way for more efficient insulin delivery methods in the future.
\end{abstract}

Keywords: IGF1receptors; InsulinReceptors; InsulinInducedtissuerecruitment; Transendothelial; Insulin Transport;

\section{Abbreviation}

FSIGT: Frequently Sampled Intravenous Glucose Tolerance; Vd: Volume of Distribution; TET: Transendothelial Transport of Insulin; eNOS: Endothelial Nitric Oxide Synthase; PI3K: Phosphoinositide 3 Kinase

\section{Introduction}

\section{Insulin Pharmacodynamics}

Insulin is released in response to glucose stimulation of pancreatic beta cells. Glucose is transported inside the pancreatic beta cells by GLUT 2 receptors [1]. After internalization it is metabolized in glycolytic pathway to produce ATP's [2]. Increased ATP/ADP ratio deactivates Potassium channels, thus increasing the concentration gradient across the cell membrane. This causes membrane depolarization [3]. This depolarization activates Ca channels and cause an increase in intracellular $\mathrm{Ca}^{2+}$ levels and exocytosis of Insulin [4]. After secretion, insulin is extracted from the portal blood by hepatocytes and acts on hepatocytes for glucose utilization [5]. Insulin binds to GLUT4 receptors in skeletal muscles and adipocytes. Skeletal muscle is the main site of action of insulin for glucose disposal [6]Glucose internalization in these tissues is largely dependent on GLUT4 receptors [7]. Any defect in GLUT4 may result in impaired glucose metabolism in target tissues [8].

\section{Transendothelial transport as the rate limiting step}

TET transport of insulin is the rate limiting step in time pharmacokinetic profile of insulin [9].This was observed in experiments utilizing glucose clamp technique. There was a time delay between achieving steady state insulin concentration in the plasma and thoracic duct lymph collections while the gradient between plasma and interstitial fluid insulin concentrations remained constant. [10] Thoracic duct lymph collections were considered representative of interstitial fluid. These measurements and delay was incorporated in Bergman's Minimal Model [10]The rate of glucose utilization, in these experiments, corresponds very closely to the lymph insulin concentrations. [11] The observed time delay in the insulin action profile was due to the time taken for the insulin level in the interstitium to rise. These observations suggested a rate limiting barrier between Plasma and interstitial fluid [12]. But there was an argument that insulin might take time to reach the thoracic duct lymph because of the slower lymph flow. Therefore, another technique was used in which micro dialysis catheters were used to measure interstitial fluid insulin concentrations directly during hyperinsulinemic glucose clamp. It also demonstrated the same time delay of app.20 min. [13]Dysfunction of this endothelial barrier is now considered to be a major contributing factor for type 2 diabetes, obesity and metabolic syndrome. [47]

\section{Capillary Recruitment and insulin uptake by endothelial cells as rate limiting step}

Another rate limiting step in glucose delivery was proposed because of the observations that the decreased gradient between plasma and interstitial fluid insulin concentration at pharmacological doses was contributed by the increase in 
capillary surface area due to capillary dilation and recruitment [15].

Increased permeability of capillary wall in response to hyperinsulinemia [16], might explain the increase in tissue volume during hyperinsulinemic clamp. But the effect is too small to quantitatively act as a single contributor. Secondly, there is contradictory evidence to transcapillary escape rate of protiens. One study demonstrated that this effect of insulin is seen only in NIDDM patients while another study shows $14 \%$ decrease in serum albumin levels after hyperinsulinemic clamp even in non diabetic patients, although the serum insulin levels achieved in these two groups were similar. [17] This microvascular recruitment is associated with insulin secretion even before an increase in the muscle blood flow [18]. This recruitment is found to be blunted in obese [19]. There is delayed transcapillary transport of insulin into muscles [20] and there is increased degradation of insulin suggested as contributing causes of insulin resistance. If the flow of blood into the muscle is restored, the $\mathrm{A}-\mathrm{V}$ glucose difference should increase, however this was not demonstrated by a study that showed that restoring blood flow in these subjects produced only a small effect on the glucose uptake in muscle [21]

\section{Microvascular pacemakers}

The microvascular pacemaker at the arterioles oscillates at around 18 cycles/min [22] Insulin is also proposed to increase the open time of arterioles and causing tissue recruitment of previously unperfused capillary beds. When the perfusion to a muscle capillary bed increases it also increases the aerobic metabolism as compared to anaerobic metabolism in normal states. [23]

\section{Volume of distribution}

The Volume of distribution for the glucose increases to $40 \%$ by hyperinsulinemia during forearm balance technique. This increase may be explained by the expansion of interstitial volume by either 1) increase in blood flow to the tissues or 2) Capillary Recruitment. The greater cellular surface area available to insulin for action due to tissue recruitmentmay can be the cause of increased glucose uptake in that compartment [23]. During forearm balance technique, the increase in capillary recruitment is observed within 20 min after giving insulin. This effect is seen earlier than any increase in glucose uptake or blood flow. This effect continues to increase $80-120 \mathrm{~min}$ after beginning the infusion. While the brachial artery blood flow did not increase till 100 min after the start of insulin infusion. Despite the increase in capillary perfusion, the extraction fraction of insulin and its clearance decreased at 80-120 min while the insulin levels were within physiological range [24]. This either points to a saturable process for the transport of insulin across the endothelial barrier or a saturable cellular uptake process of insulin to act on muscle cells and induce glucose uptake.

In a later study on humans, the rate of clearance of insulin [extraction fraction] from muscle capillaries decreased during hysperinsulinemia, even in the presence of increased microvascular volume and muscle blood flow suggesting that a saturable process involves the transport of insulin across muscle capillaries [15]

\section{Confounding factor in the study of acylated insulin delivery in experiments}

Initial studies using dog hind limb lymph collection for NN304 acylated insulin demonstrated that there was an incremental increase in the level of acylated insulin level in the deep hindlimb lymph collection even after the saturable doses of normal insulin were given. It was believed that transport of insulin across capillary endothelial cells was not a saturable process [25].

The factor that might have influenced the time action profile of the insulin is the type of insulin used in experiments. There are different times to peak and duration of action for different insulins [26]. For example, the half-life of insulin increases by seven fold and the time of onset by twofold if the amino group at B29 is acylated [27]. It may be responsible in decreased clearance of insulin from ISF. Insulin circulates in the blood in monomeric form and gets absorbed across capillaries [28]. Its molecule was first seen by Single Crystal X-ray analysis done by Crawfoot et al. [29]. It has an A chain wrapped around the B chain. Any alteration in the residues on the A chain or B23-30 dramatically alters the interaction of insulin with its receptors [30].

\section{Proposed Methods of TET insulin transport}

There is also evidence that insulin alters the endothelial cells morphology and permeability characteristics. Endothelium is a semipermeable membrane. There are signaling pathways that alter the interendothelial junctions making the interendothelial pathway leakier. There are different routes defined for transendothelial transport 1) Paracellular 2) Transcellular. There is evidence that insulin acts on endothelial cell insulin receptors via PI3K, MEK, Insulin receptor tyrosine kinase and the cSrc tyrosine kinase receptors and facilitates its uptake. This uptake is inhibited by the inflammatory cytokines [31].

\section{Paracellular route}

In paracellular route, molecules travel between the cells when the actin filaments in cell cytoskeleton get activated due to activation of MLCK pathway. This puts a stretch on the cell membrane resulting in leaky cell junctions. [32]. Insulin has been demonstrated to affect the tight junction mediated paracellular transport in cultured intestinal epithelial cells [33].

\section{Caveolins}

Caveolins are intracellular organelles in endothelial cells that are phosphorylated to transport insulin through the cell to the interstitium [34, 35]Insulin signaling may be the first step in its transendothelial transport mediated by PI-3 Kinase, csrc Kinase, general tyrosine kinase and the mitogen activated protein kinase. This is a conclusive evidence of the role of endothelial receptors in TET transport of insulin [31].

Insulin is internalized with caveolin 1 in vascular endothelial cells [36]. This process is facilitated by actin filaments through PI3K/Akt pathway [37]. A defect in cortical F actin filaments/ PIP2 may be an underlying cause of insulin resistance resulting 
in reduced activity of GLUT4 receptors [38]. After internalization, insulin might get degraded or externalized at a rate dependent on insulin receptor occupancy and temperature $[39,40]$. It also proposes a notion that vascular endothelial compartment may act to control blood insulin levels as well [41].

\section{Cellular sub compartments}

Cellular sub compartments may act as a reservoir for peripheral insulin [42]. The endothelial cells may accumulate insulin against its concentration gradient up to five times. This process is mediated by PI3K/Akt pathway. This is a saturable process hence might act as a rate limiting step [43].

\section{Insulin receptor 2 pathway}

Demonstration of another pathway IRS 2 linked to IR/IGF1 receptors that stimulates the PI3K pathway for internalization of insulin [44]; involvement of IGF 1 receptors for transport of insulin across endothelium at higher concentrations [45] ; and, in vitro studies by King et al. That demonstrated that the transport of radiolabeled insulin across bovine aortic endothelial cells from extra vascular to intravascular space was not inhibited by the presence of normal insulin, [46] suggesting alternative pathways for insulin transport in pharmacological ranges.

\section{Conclusion}

Thus studies to utilize direct visualization of the proposed receptors by electron microscopy on the abluminal side of endothelial lining will help in conclusively identifying these receptors. Such a discovery can greatly facilitate our understanding of the available subcutaneous insulin delivery methods. It will also help us in the development of effective insulin formulations and delivery models that have more stable and predictable time action profiles. Discovery of such receptors will aid in the future of artificial pancreas. Currently, artificial pancreas consists of a glucose sensing module that is connected to a subcutaneous insulin delivery system. The delivery, efficacy and potency of insulin largely depends on the surrounding milieu of the insulin delivery site. Up regulation or down regulation of subcutaneous insulin transport receptors may be contributing in the variability of insulin response in diabetics. Hence development of excipients, that may up regulate the insulin transport receptors, injected with the subcutaneously delivered insulin, may help in developing more effective artificial pancreas models. Discussions with Dr Jeffrey Joseph, Vice Chairman and Director of Thomas Jefferson University Artificial Pancreas Centre, Department of Anesthesiology, Philadelphia.

\section{References}

1. Efrat $S$, Tal M, Lodish HF. The pancreatic $\beta$-cell glucose sensor. Trends in biochemical sciences. 1994;19(12):535-538. DOI:dx.doi. org/10.1016/0968-0004(94)90056-6.

2. Matschinsky F, Ellerman J. Metabolism of glucose in the islets of Langerhans. Journal of Biological Chemistry. 1968;243(10):27302736.

3. Cook DL, Satin LS, Ashford ML, Hales CN. ATP-sensitive K+ channels in pancreatic $\beta$-cells: spare-channel hypothesis. Diabetes. 1988;37(5):495-498. DOI:dx.doi.org/10.2337/diab.37.5.495.

4. Gauthier BR, Wollheim CB. Synaptotagmins bind calcium to release insulin. American Journal of Physiology-Endocrinology and Metabolism. 2008;295(6):E1279- E1286. DOI: 10.1152/ ajpendo.90568.2008.

5. Chap Z, Ishida T, Chou J, Hartley CJ, Entman ML, Brandenburg D, et al. First-pass hepatic extraction and metabolic effects of insulin and insulin analogues. American Journal of Physiology-Endocrinology And Metabolism. 1987;252(2):E209-E217.

6. DeFronzo R, Jacot E, Jequier E, Maeder E, Wahren J, Felber J. The effect of insulin on the disposal of intravenous glucose: results from indirect calorimetry and hepatic and femoral venous catheterization. Diabetes. 1981;30(12):1000-1007.

7. James DE, Brown R, Navarro J, Pilch PF. Insulin-regulatable tissues express a unique insulin-sensitive glucose transport protein. 1988;333(6169):183-185.

8. Abel ED, Peroni O, Kim JK, Kim Y-B, Boss O, Hadro E, et al. Adiposeselective targeting of the GLUT4 gene impairs insulin action in muscle and liver. Nature. 2001;409(6821):729-733. DOI:10.1038/35055575.

9. Chiu JD, Richey JM, Harrison LN, Zuniga E, Kolka CM, Kirkman E, et al. Direct administration of insulin into skeletal muscle reveals that the transport of insulin across the capillary endothelium limits the time course of insulin to activate glucose disposal. Diabetes. 2008;57(4):828-835. doi: 10.2337/db07-1444.

10.Bergman RN. Toward physiological understanding of glucose tolerance: minimal-model approach. Diabetes. 1989;38(12):15121527.

11. Miles PD, Levisetti M, Reichart D, Khoursheed M, Moossa A, Olefsky JM. Kinetics of insulin action in vivo: identification of rate-limiting steps. Diabetes. 1995;44(8):947-953.

12. Yang YJ, Hope ID, Ader M, Bergman RN. Insulin transport across capillaries is rate limiting for insulin action in dogs. Journal of Clinical Investigation. 1989;84(5):1620-1628.doi: 10.1172/JCI114339.

13. Jansson P-AE, Fowelin JP, Von Schenck HP, Smith UP, Lönnroth PN. Measurement by microdialysis of the insulin concentration in subcutaneous interstitial fluid: importance of the endothelial barrier for insulin. Diabetes. 1993;42(10):1469-1473.

14. Pinkney JH, Stehouwer CD, Coppack SW, Yudkin JS. Endothelial dysfunction: cause of the insulin resistance syndrome. Diabetes. 1997;46(Supplement 2):S9-S13.

15. Steil GM, Ader M, Moore DM, Rebrin K, Bergman RN. Transendothelial insulin transport is not saturable in vivo. No evidence for a receptor-mediated process. The Journal of clinical investigation. 1996;97(6):1497-1503. doi: 10.1172/JCI118572.

16. Hilsted J, Christensen NJ. Dual effect of insulin on plasma volume and transcapillary albumin transport. Diabetologia. 1992;35(2):99-103.

17. Nestler JE, Barlascini CO, Tetrault GA, Fratkin MJ, Clore JN, Blackard WG. Increased transcapillary escape rate of albumin in nondiabetic men in response to hyperinsulinemia. Diabetes. 1990;39(10):12121217.

18. Barrett E, Eggleston E, Inyard A, Wang H, Li G, Chai W, et al. The vascular actions of insulin control its delivery to muscle and regulate the rate-limiting step in skeletal muscle insulin action. Diabetologia. 2009;52(5):752-764. doi: 10.1007/s00125-009-1313-z.

19. Clerk LH, Vincent MA, Jahn LA, Liu Z, Lindner JR, Barrett EJ. Obesity blunts insulin-mediated microvascular recruitment in human forearm muscle. Diabetes. 2006;55(5):1436-1442. 
20.Sjostrand M, Gudbjornsdottir S, Strindberg L, Lonnroth P. Delayed transcapillary delivery of insulin to muscle interstitial fluid after oral glucose load in obese subjects. Diabetes. 2005;54(1):152-157.

21. Holmang A, Muller M, Andersson OK, Lonnroth P. Minimal influence of blood flow on interstitial glucose and lactate-normal and insulinresistant muscle. The American journal of physiology. 1998;274(3 Pt 1):E446-E452.

22. Meyer J, Lindbom L, Intaglietta M. Coordinated diameter oscillations at arteriolar bifurcations in skeletal muscle. American Journal of Physiology-Heart and Circulatory Physiology. 1987;253(3):H568-H573.

23. Bonadonna RC, Saccomani MP, Del Prato S, Bonora E, DeFronzo RA, Cobelli C. Role of tissue-specific blood flow and tissue recruitment in insulin-mediated glucose uptake of human skeletal muscle. Circulation. 1998;98(3):234-241.

24.Eggleston EM, Jahn LA, Barrett EJ. Hyperinsulinemia Rapidly Increases Human Muscle Microvascular Perfusion but Fails to Increase Muscle Insulin Clearance Evidence That a Saturable Process Mediates Muscle Insulin Uptake. Diabetes. 2007;56(12):2958-2963. DOI:10.2337/ db07-0670.

25. Hamilton-Wessler M, Ader M, Dea MK, Moore D, Loftager M, Markussen J, et al. Mode of transcapillary transport of insulin and insulin analog NN304 in dog hindlimb: evidence for passive diffusion. Diabetes. 2002;51(3):574-582.

26.Gerritzen F. The classification of various insulins. British medical journal. 1953;2(4844):1030-1031.

27. Myers SR, Yakubu-Madus FE, Johnson WT, Baker JE, Cusick TS, Williams VK, et al. Acylation of human insulin with palmitic acid extends the time action of human insulin in diabetic dogs. Diabetes. 1997;46(4):637-642.

28. Azerad E. [Biochemistry of insulin (structure, synthesis, antigenicity, circulating forms, inhibitory antagonists)]. Pathologie et biologie. 1965;13(21):1103-17.

29. Crowfoot D. X-ray single crystal photographs of insulin. Nature. 1935;135:591-592. doi:10.1038/135591a0

30. Blundell TL, Cutfield JF, Cutfield SM, Dodson EJ, Dodson GG, Hodgkin DC, et al. Three-dimensional atomic structure of insulin and its relationship to activity. Diabetes. 1972;21(2 Suppl):492-505.

31. Wang $\mathrm{H}$, Wang AX, Liu Z, Barrett EJ. Insulin signaling stimulates insulin transport by bovine aortic endothelial cells. Diabetes. 2008;57(3):540547. DOI:10.2337/db07-0967.

32. Mehta D, Malik AB. Signaling mechanisms regulating endothelial permeability. Physiological reviews. 2006;86(1):279-367. DOI:10.1152/physrev.00012.2005.

33. McRoberts JA, Aranda R, Riley N, Kang H. Insulin regulates the paracellular permeability of cultured intestinal epithelial cell monolayers. Journal of Clinical Investigation. 1990;85(4):1127-1134. doi: 10.1172/JCI114544
34. Oh P, McIntosh DP, Schnitzer JE. Dynamin at the neck of caveolae mediates their budding to form transport vesicles by GTP-driven fission from the plasma membrane of endothelium. The Journal of cell biology. 1998;141(1):101-114.

35. Wang H, Wang AX, Aylor K, Barrett EJ. Caveolin-1 phosphorylation regulates vascular endothelial insulin uptake and is impaired by insulin resistance in rats. Diabetologia. 2015;58(6):1344-1353. doi: 10.1007/s00125-015-3546-3.

36. Fagerholm S, Ortegren U, Karlsson M, Ruishalme I, Stralfors P. Rapid insulin-dependent endocytosis of the insulin receptor by caveolae in primary adipocytes. PloS one. 2009;4(6):e5985. doi: 10.1371/ journal.pone.0005985.

37. Wang H, Wang AX, Barrett EJ. Insulin-induced endothelial cell cortical actin filament remodeling: a requirement for trans-endothelial insulin transport. Molecular endocrinology. 2012;26(8):1327-1338. doi: 10.1210/me.2012-1003.

38. McCarthy AM, Spisak KO, Brozinick JT, Elmendorf JS. Loss of cortical actin filaments in insulin-resistant skeletal muscle cells impairs GLUT4 vesicle trafficking and glucose transport. American journal of physiology Cell physiology. 2006;291(5):C860-C868. DOI: 10.1152/ ajpcell.00107.2006.

39. Bottaro DP, Bonner-Weir S, King GL. Insulin receptor recycling in vascular endothelial cells. Regulation by insulin and phorbol ester. The Journal of biological chemistry. 1989;264(10):5916-5923.

40. Kaiser N, Vlodavsky I, Tur-Sinai A, Fuks Z, Cerasi E. Binding, internalization, and degradation of insulin in vascular endothelial cells. Diabetes. 1982;31(12):1077-1083.

41. Sodoyez JC, Sodoyez-Goffaux FR, Moris YM. 125I-insulin: kinetics of interaction with its receptors and rate of degradation in vivo. The American journal of physiology. 1980;239(1):E3-E8.

42. Zeleznik AJ, Roth J. Demonstration of the insulin receptor in vivo in rabbits and its possible role as a reservoir for the plasma hormone. The Journal of clinical investigation. 1978;61(5):1363-1374. doi: $10.1172 / J C I 109054$

43. Genders AJ, Frison V, Abramson SR, Barrett EJ. Endothelial cells actively concentrate insulin during its transendothelial transport. Microcirculation. 2013;20(5):434-439. doi: 10.1111/micc.12044.

44. Araki E, Lipes MA, Patti ME, Bruning JC, Haag B, 3rd, Johnson RS, et al. Alternative pathway of insulin signalling in mice with targeted disruption of the IRS-1 gene. Nature. 1994;372(6502):186-190.DOI: $10.1038 / 372186 \mathrm{a} 0$

45.Wang H, Liu Z, Li G, Barrett EJ. The vascular endothelial cell mediates insulin transport into skeletal muscle. American journal of physiology Endocrinology and metabolism. 2006;291(2):E323-E332.

46. King GL, Johnson SM. Receptor-mediated transport of insulin across endothelial cells. Science. 1985;227(4694):1583-1586.: 